\title{
LA PERSPECTIVA DEL TRANS/POSTHUMANISMO EN LA PIEL INTRUSA (2019) DE YANINA ROSENBERG
}

\author{
Graciela Sarti \\ Universidad de Buenos Aires - UNTREF \\ gcsarti@yahoo.com
}

Resumen: Este trabajo aborda el análisis de dos cuentos incluidos en el libro La piel intrusa (2019) de la argentina Yanina Rosenberg (1980): "Mariposas en la pared" y "El peor castigo". Se ofrece un análisis de la construcción de esos relatos desde el punto de vista materno, ligado al tema del doble artificial, en este caso, el hijo. Pretende leer en estos materiales la cuestión transhumanista, puesta en foco desde la lente del feminismo trasgresor de Donna Haraway. Lo femenino en general y lo materno en particular aparecen en estos textos sometidos a debate.

Palabras clave: cuento, doble, maternidad, feminismo, post/transhumanismo

\section{YANINA ROSENBERG'S LA PIEL INTRUSA (2019) IN TRANS/POSTHUMANIST PERSPECTIVE}

\begin{abstract}
This paper deals with the analysis of two short stories included in the book La piel intrusa (2019) by Argentinean Yanina Rosenberg (1980): "Mariposas en la pared" and "El peor castigo". This study analyzes the construction of those stories from the mother's point of view, linked to the subject of the artificial double, in this case, the son. It pretends to read in these materials the transhumanist question, put in focus from the lens of the transgressive feminism of Donna Haraway. The feminine in general and the maternal in particular appear in these texts under debate.
\end{abstract}

Keywords: short story, alter ego, maternity, feminism, post/transhumanism

DOI: https://doi.org/10.24029/lejana.2020.14.1670

Recibido: el 31 de agosto de 2020

Aceptado: el 18 de diciembre de 2020

Publicado: el 26 de febrero de 2021 
La publicación en 2019 de La piel intrusa, primer libro de cuentos de Yanina Rosenberg, puso a la autora en el escenario de la "nueva narrativa argentina"1 — con antelación había sido premiada por el Fondo Nacional de las Artes por una novela, Momento Estocolmo (2016), aun no publicada aunque estaría próxima a serlo-. A su vez en 2017 La piel intrusa había obtenido un segundo premio en el concurso Fundación El Libro; ${ }^{2}$ el jurado estuvo constituido por Luisa Valenzuela, Abelardo Castillo, Pablo De Santis, Antonio Skármeta y Daniel Divinsky. Con anterioridad, Rosenberg había publicado cuentos en medios periodísticos de máxima circulación - los diarios argentinos Perfil y Clarín - y en la revista literaria Granta. ${ }^{3}$

Esta sumatoria de premios, pero sobre todo la aparición del contario como opera prima, fueron motivo de varias notas periodísticas y alguna entrevista por parte de la crítica especializada argentina y española. Se saludó a Rosenberg como miembro de una generación de narradoras mujeres, junto a Mariana Enríquez, Gabriela Cabezón Cámara o María Gainza (Criales, 2019); a pocos días de aparecido el libro se subrayó su vinculación con lo siniestro y el cuestionamiento del "sentimiento de la maternidad que se da por hecho" que habita en sus páginas (Vanguardia, 2019); se recorrieron temas centrales de su narrativa tales como el cuerpo, la culpa, la maternidad, el doble, y se mencionaron los puntos de partida con los que construye sus relatos: una imagen, una frase, un final (Gascón, 2019); en breve pero ajustada reseña, se subrayó el valor de lo no dicho y el clima de pesadilla de su mundo ficcional (Boix, 2019).

Este conjunto de notas es parte de las que vienen publicándose en torno a cierto boom de narrativa argentina femenina: saludo generalizado a la aparición de una nueva generación de escritoras, que bien podría ponerse en cuestión o matizarse, dado que la literatura producida por mujeres no es ninguna novedad en este medio, de Silvina Ocampo a Hebe Uhart. ${ }^{4}$ Sin embargo, en el caso que nos ocupa, el sesgo femenino será central, bien que

\footnotetext{
${ }^{1}$ En 2016, Elsa Drucaroff revisó la conceptualización que había desarrollado en su polémico Los prisioneros de la torre (2011) respecto de una Nueva Narrativa Argentina. En aquel libro había postulado la existencia de una vasta generación literaria de jóvenes "no primaverales", derrotados sin combatir a partir de las experiencias de posdictadura y del neoliberalismo de los noventa en Argentina. Con el objetivo expreso de caracterizar y profundizar en la producción de la segunda generación de posdictadura, Drucaroff traza en este nuevo artículo una semblanza que incluye, desde lo narrativo, la puesta en marcha de la acción (31), "el regreso de la pulsión por contar historias y explorar en los géneros masivos de la literatura moderna y del cine: el policial negro y el thriller, las aventuras, la ciencia-ficción, el terror y el gore" (32), la recuperación del enigma y la experimentación con la subjetividad femenina, entre otros rasgos (32). No es el caso aquí de abrir el debate sobre la pertinencia exacta de esta caracterización en el caso que nos ocupa, aunque los paralelos son evidentes. Solo advertir que, por ejemplo, la inclusión del cuento de Rosenberg "Orgullo estratégico", en el proyecto Audiocuentos de la Nueva Narrativa Argentina, apunta a ubicarla en esta corriente.

${ }^{2}$ Dicha Fundación inicia su constitución en Buenos Aires en 1974, con el concurso de entidades como la Sociedad Argentina de Escritores, la Cámara Argentina del Libro, la Cámara Argentina de Publicaciones y el Sector de Libros y Revistas de la Cámara Española de Comercio, entre otras. Desde 1975 organiza la Feria Internacional del Libro: desde el autor al lector, que es la feria mundial del libro de habla hispana de mayor envergadura. Naturalmente, su premio anual es de gran relevancia.

${ }^{3}$ Allí publica "El sueño de los millonarios" en 2016. Este cuento no pertenece a La piel intrusa.

${ }^{4}$ Por cierto que es certera la afirmación de Ana Gallego Cuiñas, en el sentido de que esta eclosión de literatura argentina producida por mujeres en el siglo XXI se venía gestando desde los setenta y ochenta; también, que en esta "novísima" narrativa, más que la inclusión de un cierto elenco de temas, lo definitorio es, justamente, "la irrupción masiva y reveladora, de mujeres escritoras y poéticas feministas" (2020: 72-73), hecho que aún no ha sido debidamente atendido por la crítica más que en la consideración de casos puntuales. En su análisis de la obra de Selva Almada, Mariana Enríquez y Samanta Schweblin, Gallego Cuiñas señala que un factor que las une es "la naturaleza de sus propuestas estéticas, que contemplan un manejo subversivo - feminista - del lenguaje, de temas y problemas - globales - que apuntan a la deconstrucción de categorías genéricas binarias y de ciertos
} 
intersecado con temas variables y mundos de diversa procedencia. Nacida en 1980, Rosenberg suma a una primera graduación de farmacéutica una segunda de licenciada en Letras. Marcas de su generación y su formación se hacen sentir en sus relatos.

\section{El contario}

En 2017, para la presentación al concurso de Fundación El Libro, este volumen se llamaba Los afueras, que es el título del último de sus cuentos; para su publicación en 2019 adquiere este otro de La piel intrusa que, sin corresponder a ninguno de los cuentos, bien puede enlazarlos a todos a partir de la evocación de una ajenidad que invade el cuerpo y la sensibilidad. Catorce cuentos constituyen este bien ensamblado contario; ${ }^{5}$ la palabra aplica perfectamente, dada la unidad y coherencia de su estructura, a la que aludiremos solo brevemente.

Una de las primeras y más evidentes notas comunes es la enunciación en primera persona. Once de los cuentos tienen una narradora protagonista, femenina. Otros dos están narrados en tercera persona, pero desde una casi absoluta focalización interna en la protagonista: son los cuentos segundo y tercero, "Mariposas en la pared" y "Como se debe". Tan solo el primer cuento del libro, "Septiembre en la piel", tiene un narrador masculino, en primera persona y homodiegético: no es casual. En este primer, breve cuento, un hombre asiste asombrado a la transformación de su mujer. Así el íncipit: "Un aire a pasto mojado inundaba la habitación” (Rosenberg, 11). A partir de allí, como en el resto de los relatos, desde la situación cotidiana se dispara el ámbito de lo maravilloso —en el canónico sentido que les diera Todorov (1995) - . En este caso la mujer, Guapi, cual Gregorio Samsa vegetal, aparece cubierta de pasto; luego saldrán de su piel margaritas, hojas: evidentemente el título del cuento alude a este florecimiento de la primavera del hemisferio austral en la piel de la protagonista. El cambio es saludado como signo positivo, tanto por Guapi — que no habla pero mira "¿asombrada, divertida?” (12)—, como por su madre — "una bendición que, sin duda, esperaba desde hacía tiempo" (13)— y por el narrador — "si estás hermosa" (12)—. No así por la suegra, naturalmente, cosa que no tiene la menor importancia. El tono jocoso, feliz, de estas primeras páginas, muta cuando en algún momento "comenzamos a hacer las cosas mal” (13) y Guapi empieza a pudrirse. Ningún tratamiento resulta eficaz para la caída de sus hojas, para combatir los parásitos, el olor, la pelusa blanquecina de hongos que la recubre. Finalmente el narrador no encuentra otra salida que enterrarla una noche en la plaza, esperando "que al fin pudiera ser feliz" (15); esperando, siempre, en esa plaza, que tal vez vuelva a florecer. Guapi, privada de palabra, jamás podrá decir si acepta o no esta decisión. Muy claramente, la ubicación de este cuento en el inicio alude a una transformación femenina que resulta tan milagrosa como incomprensible, y que allí donde se vuelve inmanejable es quitada de la vista, enterrada para quedar latente, en permanente espera de una nueva mutación.

imaginarios heteronormativos diseminados por la ideología patriarcal en relación con las ideas de maternidad, la sexualidad, el amor romántico y la violencia machista" (76). Estos conceptos podrían aplicarse, como se verá, al caso que aquí tratamos.

${ }^{5}$ Ex profeso se utiliza aquí el término contario y no cuentario, como modo de aludir no ya a una mera recopilación de cuentos, con su margen de posible arbitrariedad, sino a un ensamblado en el que los cuentos seleccionados ocupan un lugar en una estructura, al modo de las cuentas en un diseño ornamental. 
Los otros trece cuentos, en cambio, desarrollan diversos modos del punto de vista femenino, no solo por la focalización narrativa en la protagonista, sino también por la variedad temática que abarcan: la maternidad, las relaciones maritales, la atracción sexual. El varón, cuando aparece, resulta ya seductor para volverse violento, ya amenazador u ominoso, ya distante o ausente, tan incomprensible siempre como la Guapi de "Septiembre en la piel". Por poner dos ejemplos claros: en "Guazuvirá", tres jóvenes arriban a un pequeño pueblo donde se las espera para cumplir cierto misterioso "contrato"; quien las recibe, un atractivo hombre llamado significativamente Adán, prepara una suerte de espectáculo que termina siendo, para sorpresa y horror de la protagonista, un acto de vampirismo. Sobre el final del cuento podemos presumir que este "espectáculo" se llevará la vida de una de las amigas, quien se entrega gozosamente a la acción. En "Calor dolor rubor tumor", un viaje para hacer un trámite familiar en el interior del país se transforma en una pesadilla donde la protagonista, acosada por un estado de enfermedad creciente, se cruza con un hombre - nuevamente, muy atractivo-, quien deposita en ella a su hijo pequeño sin ningún aviso, y durante muchos días. Una vez que ella ha establecido una relación maternal con la criatura, el hombre reaparece para despojarla y encerrarla. En cualquiera de los casos, no se dejan adivinar las motivaciones de los personajes masculinos, y se pasa fácilmente de la seducción a la inesperada agresión. El relato homodiegético del personaje femenino permite advertir el traslado de la intensidad de la primera atracción erótica a la sorpresa progresiva, y finalmente a la angustia.

Los relatos de este libro parten de lugares tan reconocibles como un departamento, un barrio de Buenos Aires, una localidad del litoral. También las situaciones de partida son cotidianas: el despertar por la mañana, la ducha, preparar un desayuno, realizar un trámite, acudir a una cita en el colegio del hijo. En ese contexto se instalan en principio lo extraño, ${ }^{6}$ y en varios casos lo maravilloso; o más ajustadamente, y siguiendo la conceptualización de Rosalba Campra, un choque, una violación del orden de "lo real" que le proponen al lector "este escándalo racional: no hay sustitución de un orden por otro sino coincidencia" (2008: 27). Se trata de relatos ya extraños, ya fantásticos, entonces, que se sitúan en un traspaso de fronteras, no meramente por insertar la extrañeza inquietante en el ámbito cotidiano - cosa que define lo siniestro - sino por la violencia de la acción en ese traspaso. La vía de entrada de estos otros mundos es ante todo el diálogo trunco y lleno de sobreentendidos, que va creando preguntas sobre lo no dicho, lo que acecha desde fuera de la escena y se constituye en amenaza: "es suficiente el silencio sobre la causa, sobre el porqué, para desbaratar la noción de realidad" (Campra, 2008: 128). En algún momento se produce el paso inusitado de la acción cotidiana a una desatada violencia física —-Guazuvirá", "Evelina", "Calor Dolor Rubor Tumor", "Una tibieza elástica"-, en algunos cuentos con ribetes de erotismo.

\footnotetext{
${ }^{6}$ Ejemplos de lo extraño en este contario son los cuentos "El monstruo" y "Pajaritos de neón". En el primero, la protagonista llega a la casa de su madre enferma y escucha una conversación de esta con un interlocutor invisible; en verdad su madre guarda en frascos los tumores de sucesivas operaciones y con ellos dialoga. La sorpresa y horror iniciales se transforman en piedad y comprensión. En el segundo, una comida rápida y un viaje en tren subterráneo de una madre con su hija pequeña, son el marco en que la protagonista se va sumiendo en un clima de extrañeza creciente por la presencia constante de otro personaje femenino, una joven mendiga y desastrada. Finalmente, la protagonista acaba perdiendo a su hija al descender en una estación, ante la mirada de asentimiento de la mendiga. La duda del final desplaza al cuento hacia la categoría de lo fantástico-extraño en el sentido más tradicional de esos términos (Todorov, 1995: 39).
} 
Es claro reconocer una matriz cortazariana, ${ }^{7}$ pero habitada por otras influencias, cosa que señala la autora modelo en "El estimulante sabor de la libertad". La narradoraprotagonista sale de rendir un examen, para encontrarse que sus amigos no la han esperado. Parte a buscarlos por las inmediaciones — se trata claramente de un terreno conocido, la Facultad de Filosofía y Letras-, bajo el inicio de una tormenta, cuando una motocicleta casi la atropella. Entra a un bar que, curiosamente, nunca había visto antes; se ve compelida a pedir un café. Constata con sorpresa el acoso, la mirada hostil y fija de los pocos presentes, incluidos quienes atienden, que parecen estar pidiéndole o esperando algo que ignora. Es claro el recuerdo de "Ómnibus" (de Bestiario, 1951), y Rosenberg lo asume: "Atormentada protagonista de un cuento de Cortázar, comencé a teclear las uñas contra la mesa" (75). El mozo trae el café, pero lo deposita en el otro extremo de la mesa, y se sienta a bebérselo. "Creo que fue un simple parpadeo de ojos lo que me hizo saltar de Cortázar a Boris Vian" (75). La cajera toma el lugar del mozo, pasa a leer la borra de café y ve allí un accidente de moto. "Ahora sí: un personaje de Philip Dick me estrechaba la mano y me daba la bienvenida a sus renglones" (76). En síntesis notable, la autora implícita ha dado cuenta de sus influencias y de su recalada en una forma particular de la ciencia ficción. Entretanto su protagonista, al contrario de los personajes de "Ómnibus", se rebela contra el absurdo del entorno, reniega del vaticinio, se sirve compulsivamente otro café en la barra, "-Leeme ahora la borra si podés, mi borra, hubiera querido decirle a la loca de la bandana" (77), y sale a la calle saboreando su "estimulante" libertad.

A lo largo del contario se alternan maternidades locas — "Evelina", "Una tibieza elástica" - y maternidades compulsivas — "Calor Dolor Rubor Tumor-; el horror y la piedad por una madre que guarda los tumores de sus operaciones en un armario y dialoga con ellos, en "El monstruo", y el espanto de una madre que pierde a su hija en el subterráneo en "Pajaritos de neón"; la situación de vampirismo ya mencionada en "Guazuvirá" y un marido zombi, o catatónico, que desespera a su mujer en "La humedad de la culpa"; una mujer que sale a correr como si su cuerpo ya no le perteneciera y vuela llevada por el viento "Rebelión de los engranajes" - y una joven que, desde una situación de seducción, incurre en violencia extrema, tal vez asesinato - "Como se debe"-.

Que el cuento "Los afueras" esté ubicado en el cierre del volumen carga de sentido al conjunto y evoca, como en espejo invertido, al primero de los relatos. Si en "Septiembre en la piel" asistíamos a la mutación de una mujer, vuelta naturaleza, aquí también hay un acto de mutación, también de reencarnación, asumido por un conjunto de personajes, al que una mujer se niega. En un ámbito de encierro y extrañamiento, un conjunto de habitaciones y pasillos, que podrían evocar tanto el espacio de la secuencia final de 2001: A Space Odyssey

\footnotetext{
${ }^{7}$ Varios son los procedimientos que pueden ubicarse en esta perspectiva cortazariana. Ante todo, y como el más evidente, este uso de los silencios, ya mencionado, en el que se pueden percibir tanto las elisiones de las causas mientras se asiste al despliegue de los efectos, como, a la inversa, se desarrollan las causas pero se escamotean los efectos (Campra, 2008: 133-134). También, y en líneas generales, se advierte en estos cuentos esa concepción de lo fantástico que Mario Goloboff encuentra como propia de Cortázar: "la capacidad de estirar los límites de lo real, como para hacer entrar, en lo que tradicionalmente llamamos realidad, todo aquello que es insólito, excepcional, extraordinario" (2004: 279). Notable, también, cómo en el último de los cuentos, "Los afueras", pueden aplicarse nociones de espacialización del género, como las propone Beatriz Sarlo para su lectura de Cortázar: como se verá de inmediato, en ese cuento el pasaje hacia el "otro lado" resulta siniestro, mientras que la imposibilidad de realizar el pasaje entre uno y otro espacio se resuelve en términos de condena (Sarlo, 2007: 265).
} 
(1968) de Stanley Kubrick como la pesadilla infernal de Huis clos (1944) de Jean-Paul Sartre, unos personajes desechos, hambrientos y muertos de frío, son compelidos a desnudarse, a observar por ventanas un afuera — ¿el destino que les aguarda? - , a seguir adelante, siempre adelante, a zambullirse en una suerte de cristal fundido y desaparecer. La narradoraprotagonista se aferra a un hombre viejo con el que ha trabado vínculo y al que decide llamar Salvador; a medio camino logra detener el tránsito, el hundimiento en ese magma, para descubrir sobre el final que de una reencarnación se trataba. La mirada de Salvador la contempla desde los ojos de un recién nacido que ve por una de las ventanas. El final la deja sola y aislada, en un mundo ya sin puertas ni ventanas, un mundo clausurado y sin salida posible. Si en "Septiembre..." había una gozosa aceptación de la mutación e hibridación de una mujer, que acababa con el alejamiento, la incomprensión y la espera de un hombre, aquí es el hombre quien ha mutado y la mujer queda en situación angustiosa y sin salida.

\section{Trans/posthumanismo y femineidad: las madres terribles en La piel intrusa}

Desde hace ya cuatro décadas se ha instalado la discusión teórica sobre posthumanismo y transhumanismo. Más allá de la temprana aparición del término "transhumanismo" en la obra de Julien Huxley en 1957, como deriva de "humanismo evolutivo" (Hottois, 2015: 176), o del término "transhumano" en Teilhard de Chardin en 1950, instalando la idea de que "es el futuro del hombre más allá del hombre por el que los hombres deben trabajar" (Hottois, 2015: 178-179), es desde el final del siglo XX y hasta el presente, el periodo sacudido por estas disquisiciones. Se haga converger ambos términos, o bien se los diferencie claramente entre una propuesta transhumanista que prolonga los valores de la Ilustración y apunta a la mejora de la humanidad, y un posthumanismo que se vincula a la postmodernidad y a las tecnociencias (Hottois, 2015: 189), está claro que la urgencia es discutir el futuro de la especie, su salvación o caída, su hibridación, su posible mutación para peor o para mejor, la posibilidad de un relevo.

Ahora bien, si en esta discusión entran en juego temas inherentes a la femineidad, intersecados con formas de la monstruosidad y, muy especialmente, con la posibilidad de la creación de autómatas, la remisión a los textos seminales de Donna Haraway se vuelve necesaria. Como bien ha señalado su prologuista Fernando García Selgas, "Haraway nos hace ver, en Ciencia, cyborgs y mujeres (1991) que simios, mujeres y organismos cibernéticos son seres limítrofes a la «auténtica identidad humana», que representan un reto y un medio de análisis para algunos de los grandes mitos de nuestra civilización, como son la ciencia, el humanismo y el feminismo" (en Haraway, 1991: 29). ${ }^{8}$ Efectivamente, a partir de la publicación del Manifiesto Cyborg en 1984, se sacuden las aguas de la crítica y la teoría. Escrito en términos de blasfemia, y con el talante combativo del manifiesto que es, propone entre otras cosas que "las fronteras entre ciencia ficción y realidad social son una ilusión óptica” (Haraway, 1991: 253); que "a finales del siglo XX “-nuestra era, un tiempo mítico, todos somos quimeras, híbridos teorizados y fabricados de máquina y organismo; en unas palabras, somos cyborgs" (254) o que "ni el lenguaje, ni el uso de herramientas, ni el

\footnotetext{
${ }^{8}$ Los inicios de Haraway la encuentran como estudiosa tanto de la Filosofía como de la Biología. Recordemos su principal aporte en cuanto a la historia de la conciencia y de la ciencia, su interés por desvelar la construcción masculina del discurso científico.
} 
comportamiento social, ni los acontecimientos mentales logran establecer la separación entre lo humano y lo animal de manera convincente" (256-257). En verdad, no se distingue entre humano y animal ni entre humano y máquina. En este marco de desdibujamiento de los límites que tradicionalmente definían humano, el cyborg aparece como la encarnación de las nuevas subjetividades fruto del impacto de las tecnociencias: desde ellas parecemos conducirnos a la autogeneración.

La crítica de Haraway es una crítica feminista, que imbrica el análisis del discurso científico con el análisis de la ficción literaria. En el capítulo final de Ciencia, cyborgs y mujeres - "La biopolítica de los cuerpos postmodernos: constituciones del yo en el discurso del sistema inmunitario"-, tras considerar los discursos de la biología y la medicina, contrastarlos con los lenguajes populares, y dimensionar en qué medida construyen subjetividades con centro en la cuestión del sistema inmunológico humano, analiza la narrativa de la escritora estadounidense Octavia Butler (1947-2006). Escritora de distopías sobre la catástrofe, la supervivencia y la metamorfosis, Butler hace centro en el cambio posthumano por traspaso de genes e hibridación; a Haraway sus novelas le resultan terreno fértil para trabajar nuevas humanidades y nuevas maternidades. Dirá la protagonista embarazada de la trilogía Xenogénesis (1987-1989): "Pero no serán humanos, y eso es lo que importa. Tú no puedes comprenderlo, pero eso es lo que importa" (Haraway, 390-394). Haraway rescata esta cita ya sobre el cierre de su trabajo, lo cual da la medida de su importancia.

Esta perspectiva puede resultar fecunda a la hora de abordar dos de los cuentos de $L a$ piel intrusa: "Mariposas en la pared" y "El peor castigo", textos que hacen centro en aquello que tradicionalmente define "lo femenino", la maternidad, y que se imbrican con el tema del doble artificial. Ambos cuentos, como se verá, pueden volver a funcionar como espejos divergentes — tal como operan el primer y último cuento del contario-.

"Mariposas en la pared" es básicamente un diálogo telefónico que la narradora, Lena, entabla con su expareja acerca de su hija, Maya. Mientras habla y discute con el hombre y consigo misma, observa fijamente una mancha de humedad en la pared, mancha con forma de mariposa. La narración parte de la duda de Lena respecto de llamar a un hombre que ya no quiere hablar con ella. "Todavía en deshabillé y con las mejillas húmedas de tanto llorar repasa el número que, si bien sabe de memoria, hace dos meses que no marca" (17). Hay algo, en el inicio de este breve cuento, que hace recordar a La voix humaine (1930) de Jean Cocteau: una mujer desesperada que se aferra a través del teléfono a un hombre que la ha dejado, que insiste en continuar una comunicación rota. "No, hoy me va a atender", se obstina (17). Finalmente Fabián atiende, lejano, mientras en Lena brota el recuerdo de los momentos de una relación que culminan en el nacimiento de la hija. El hombre desea cortar, está manejando, pero Lena se impone invocando el nombre de Maya mientras piensa que está harta de "llamarte en un rato" (18). Y dispara una elíptica frase: "Ya sé qué hacer con ella" [...] - Es una clínica en Cinco Saltos, ellos se ocupan de todo, hasta de los estudios previos, del papeleo... nosotros no tenemos que hacer nada, solo firmar" (18-19).

Mientras Fabián aún intenta cortar la comunicación, siempre atento a su auto, a través de frases truncas Lena remite a algo que ocurre siempre, que la angustia, porque ya no puede resolver por más que intente. Apoya sus dichos con un relato banal de desobediencia. El hombre acaba por calificarla, "seguís igual de chiflada que siempre" (20), mientras Lena 
recuerda un verano, juntos en la playa de Cariló, siempre absorta en la mariposa de humedad en la pared. Pero también llora al dar un giro a su relato: "no se explica que una hija odie así a su madre" (20), para pasar a preguntarse, como cualquier madre culposa, por los momentos fallidos de la crianza - "si yo no le hubiera sacado el chupete a los seis" (20)—. Las negativas y evasivas de Fabián van provocando el relato de Lena, dándole cuerpo y forma. Maya se esconde en el placard horas y horas, en el colegio prefiere sacarse fotos con las mamás de sus compañeritas, ha querido irse a vivir con su maestra, inventa cosas horribles acerca de ella. Fabián va cediendo, pero Lena ya ha tomado una decisión: "Una firma nada más, y después del resto me ocupo yo; es simple [...]. Sacan el núcleo del óvulo y lo reemplazan por el núcleo de una célula de Maya" (21). Ahora es el hombre el que está alarmado, promete ir enseguida. Pero Lena ya no quiere verlo, está decidida. Acerca su cara a la mariposa para, "con precisión de madre, tomar la temperatura de la pared" (22). Y es Fabián quien, aún no queriendo creer, vuelve a preguntar. Ella responde: “...es eso o ya sabés, ¿preferís ya sabés?” (22). Fabián suplica. Lena responde comparando a su hija con la leche cortada, "si está vencida, ya está" (22). Luego afirma que continuará adelante, empezando de cero, "solita". Ya no escucha el ruego del hombre que se apura por llegar: “... igualita a la de ahora pero mejor, porque con la experiencia una ya sabe y..." (22). Lena corta y observa la pared pensando en un lindo "empapelado de mariposas para su nueva Maya" (23).

En el equivalente de tres páginas, el cuento ha ido llevando desde la situación dolorosa y corriente de la mujer abandonada y desbordada, que busca el contacto con el hombre que ha perdido, a este nuevo escenario donde irrumpe el tema de la réplica del ser humano, y nada menos que en la figura de una hija. La mancha que parece mariposa va ganando presencia a lo largo del relato, primero como algo que solo tal vez recuerde una mariposa, hasta adquirir consistencia, crisálida que madura en la medida de la creciente determinación de Lena. Esa determinación pasa por la amenaza expresada en medias palabras — “o ya sabés”_, Medea moderna que cuenta con una ciencia que parece estar ya instalada y operando en la sustitución de un ser humano. Y, como Medea, logra dar vuelta la situación, poniendo al hombre en la exacta posición de súplica que ella tenía en el inicio. Es más, la ubicación de este relato como segundo del contario, inmediatamente después del único cuento que se narra desde una perspectiva masculina, bien puede pensarse como un punto de giro, un acto de pase desde una posición de sumisión a una de desquiciada dominancia. La maternidad, valor femenino naturalizado por excelencia - ya es del lugar común afirmar que la función materna es de la naturaleza y la paterna de la cultura-, ${ }^{9}$ queda borrada de un plumazo cuando las inseguridades e impotencias de una mujer llorosa se transforman en decisión feroz e inamovible, con el mero auxilio de una mancha en la pared.

Uno de los aspectos más perturbadores del trabajo de Donna Haraway es la proposición de que las mujeres compartimos con los cyborgs cierto grado de posibilidad de no ser, siempre y en todas las ocasiones, seres individuales. La analogía es, como poco,

\footnotetext{
${ }^{9}$ Gloria Alpini ha postulado que el género fantástico moderno se alimenta de construcciones míticas, dentro de las cuales el arquetipo de la Gran Madre resulta fundamental (2005: 38-39); también, que el género contemporáneo resulta un territorio de resistencia femenina, más allá de oposiciones binarias "male/female, intellect/instinct, rational/irrational, Homo sapiens/Mother-Nature" (39). Considera, más bien, que el mito de la Gran Madre es responsable de los estereotipos de mujer-muñeca y mujer-demonio, y que este estereotipo es ya registrable en las figuras mitológicas femeninas de la antigua Sumeria, Egipto, Babilonia, la Antigua Grecia y Roma (39-40).
} 
escandalosa: si, como definiera Julien Huxley en 1912, ser individual es aquel que "deja de ser funcional" al ser cortado por la mitad, en ciertos casos la maternidad pone a las mujeres en la incómoda cercanía de los gusanos, al resultar "cortadas por la mitad" pero reteniendo su función materna (1995: 370-371). Y esto dicho en tiempos de desarrollo del Proyecto Genoma Humano: es decir, en momentos en que "la diversidad humana y sus patologías fuesen domeñadas en el extenso código guardado por una oficina genética internacional" (Haraway, 1995: 369-370) y cuyo modelo es la réplica celular. La protagonista de "Mariposas en la pared" parece encarnar, en su desquiciado discurso, una aguda conciencia de estos cambios y estas incertezas. El hombre distante, no. Lo interesante del relato es la posición incómoda en que, inevitablemente, queda el lector, deseando la restitución de un orden que salve a Maya de la sustitución por una réplica transhumana, "mejorada", lo que lo arroja al deseo de restitución de un orden, ante todo, masculino.

En "El peor castigo", la situación guarda paralelos y una poderosa inversión de sentido con la anterior. Aquí la narradora-protagonista, cuyo nombre no sabremos, inicia su relato en tiempo presente, en el momento de estacionar su coche mientras escucha gritos que "se estiran como aullidos" (37). Realiza los actos comunes de conexión de la alarma, tomar su cartera, cruzar la calle, como queriendo "escapar a los gritos que, al aumentar el volumen parecen correr hacia mí" (37). Esos gritos se vuelven aullidos que "aturden como para ocultar algo, un secreto, una verdad que de ninguna manera debería revelarse" (37). Este clima ominoso desarrollado en el primer párrafo a partir de la múltiple mención de los gritos, remite inmediatamente, o parece hacerlo, en el inicio del segundo párrafo: la protagonista está entrando a un colegio, naturalmente los gritos son los de los escolares en recreo. Sin embargo, su entrada no está exenta de nuevos perfiles inquietantes. Otros padres la miran con temor, murmuran a su paso, hasta dos se abrazan como protegiéndose. La potente presencia de la directora Gentile corta esta escena: como niña encontrada en falta, esta mujer, una madre citada por la dirección del colegio, debe soportar una larga disquisición sobre los valores de la institución, discurso que culmina en acusación directa. Su hijo acaba de rociar con kerosén a varios compañeros y a un maestro: "No los quemó vivos porque no encontró fósforos" (39).

La protagonista se defiende: no puede ser, hace días que su hijo no concurre al colegio, está en cama con fiebre. La directora contraataca haciendo entrar al chico; pronto sabremos que es un adolescente o púber y se llama Tavito. Naturalmente, será expulsado del colegio. Tavito mantiene una expresión relajada, tranquila y ausente. Al salir, y ya en el auto, la madre llama a casa. Le responde el hola "asmático y algo gangoso" (41) por la fiebre, de su hijo: "Perdón mi amor, quería saber cómo estabas”. Se vuelve a su acompañante: “—¿Quién sos?[...] pero esta réplica ni se inmuta- [...] ¿Rocha te mandó?” (41). Una vez más, y como ocurre en todos los cuentos, lo cotidiano se ve interrumpido por lo fantástico, enunciado desde sobreentendidos que son incógnitas para el lector. El chico es una réplica; hay alguien llamado Rocha, de quien pueden esperarse cosas como esta. La "normalidad" se rompe por el surgimiento de un elemento extraño que, sin embargo, ya estaba allí en el horizonte de expectativas de la protagonista. El lector podrá sorprenderse, pero la narradora, no demasiado.

Ante la mudez del chico, que no responde sus preguntas, la mujer toma una súbita decisión, tal vez desencadenada porque ve que le "sonríe a las siliconas de una morocha" (42). Entra con él en un albergue transitorio, un alojamiento por horas para parejas. La burla del conserje, que la llama "mami", desencadena un párrafo notable sobre la "cartilla de rojos" de 
su rostro: una veintena de rojos enumerados como "rojo sangre, rojo labio, rojo lava", para desembocar en elementos tan diversos como una Ferrari, el óxido o el pimiento (42). La entrada en la habitación provoca el recuerdo de Rocha, un hombre lleno de "palabrerío de artista", presente "en cada adorno, cada átomo de arte"; hombre al que ha querido olvidar, tanto como a "los ocho años en que me cagó la vida a mí y al pobre Tavito" (43). La réplica sigue sin responder a palabra alguna, pero sí reacciona al estímulo de un video pornográfico que se pasa por la televisión del cuarto. La mujer cambia el dial, logrando que, al menos, se mueva incómodo: "No tiene lengua, no habla, pero sabe rogar por una porno. Bien" (44). La impotencia de la protagonista se resuelve en violencia: arranca el guardapolvo del chico, le tapa la cara con la remera, le hunde sus uñas en el pecho. La única reacción que logra es la "mano que se acelera adentro del pantalón" (45). La escena crece en violencia ya extrema: ahora lo ataca con una hoja de afeitar, "hasta cortarle de un envión una tetilla" (45); pero Tavito no grita. La inacción del muchacho la lleva a temer haberlo matado. Piensa en llamar a Rocha para que "se haga cargo" y añade una reflexión inusitada: "seguro la idea de mandarme un Tavito nuevo fue de él. Yo no sé, no sé cómo hará para que se parezcan tanto" (46). Ahora sabemos que no es la primera vez.

Todavía hay una nueva brutalidad, hunde el taco de su zapato en la entrepierna del chico. Pero él le devuelve una mirada "cercana al miedo y a la piedad, al perdón, al arrepentimiento; me mira con un gesto dolorido, casi enfermo, y entonces me acerco a besar su frente" (46-47). La protagonista cierra su relato prometiéndose "cuidarlo como debí cuidar al otro Tavito" (47).

Nuevamente en este cuento encontramos la cuestión de una maternidad jaqueada, y de la sustitución de un hijo por vía de una creación artificial. Sus diferencias con el anterior, sin embargo, son muy reveladoras. En este caso, una madre que comienza luciendo una conducta normal y contenida, en una situación aparentemente cotidiana, va entrando progresivamente en el desborde. El hombre, al que no se recurre ni se quisiera volver a ver, opera desde fuera de escena, enviando el elemento anormal que hace estallar todo marco de referencia. Si en "Mariposas en la pared" la sustitución de la hija queda enunciada como proyecto - $-\mathrm{y}$ siempre podemos esperar que Fabián llegue a tiempo para evitarlo-, en "El peor castigo" la sustitución ocurre y se nos sugiere que ya ha sucedido más de una vez. Con todo derecho, podemos preguntarnos qué pasará con el Tavito que aguarda en casa enfermo... y qué ha sucedido con el anterior, y con otros tal vez. Es el hombre quien desde fuera logra desestabilizar a la mujer y a su hijo, quien triunfa sobre ella. Y, con su accionar, desvela el rostro oculto de una maternidad aparentemente normal. Una madre que se preocupa por la fiebre de su hijo... también puede atacar armada de una Gilllette, a quien será, en definitiva, un nuevo hijo. Por otra parte, si en principio no dudamos de la condición humana de Maya, con todo derecho dudamos de la de Tavito, en cualquiera de sus versiones.

También, en ambos cuentos, podemos pensar en una inversión, un traspaso. Lena tiene un proyecto transhumano para Maya, cree que auxiliada por la ciencia puede lograr una hija mejor, exteriormente igual a la habida de su sangre, pero con una conducta adecuada, amante de su madre. La protagonista de "El peor castigo" vive en un mundo posthumano, donde la noción de humanidad ha perdido sus fronteras. La conducta animal del Tavito replicante, carente de habla pero con una sexualidad activa, dispara la violencia en la mujer. Esa violencia también cargada de sexualidad en su ataque a las tetillas, a los genitales, y en un 
ámbito destinado a la actividad sexual como es un albergue transitorio, es una de las marcas más potentes de la puesta en cuestión de la función materna. En este cuento se registra con claridad aquella indiferenciación entre animal y humano y entre animal y máquina —en este caso máquina de carne y sangre, pero máquina al fin — de la que nos hablaba Haraway.

Efectivamente, para Haraway, el mito cyborg presenta una doble cara: negativa en cuanto a que "un mundo cyborg representa la última imposición de un sistema de control en el planeta" (1995: 263); pero también esperanzadora, en tanto ese mundo cyborg "podría tratar de realidades sociales y corporales vividas en las que la gente no tiene miedo de su parentesco con animales y máquinas ni de identidades permanentemente parciales ni de puntos de vista contradictorios" (263). Algo de esta rica ambigüedad aparece en "El peor castigo". El Tavito replicante revela su ser artificial en el punto en que aparece su pura animalidad sexual, sin palabra. Y, si bien es agredido y rechazado, acaba siendo aceptado por vía de un acto de piedad. Como en el cuento anterior, el hijo biológico queda fuera de la escena, objeto de amenaza de sustitución, lo que vuelve particularmente ominoso el desenlace. El centro lo ocupa, una vez más, una maternidad vivida como fractura y conflicto. "No existe nada en el hecho de ser «mujer» que una de manera natural a las mujeres” (Haraway, 1995: 264).

\section{Bibliografía}

ROSENBERG; Yanina (2019): La piel intrusa. Madrid, Páginas de Espuma.

ALPINI, Gloria (2005): "From Female Archetypes to Female Stereotypes. Myth and Fantasy: Alienating Modes of Representation. An Interdisciplinary and Comparative Approach to «le fantastique féminin». Annali della Facoltà di Scienze della Formazione, I/2: 3546.

BOIX, Verónica: “Reseña: La piel intrusa, de Yanina Rosenberg”. La Nación, el 16 de junio de 2019, disponible en: https://www.lanacion.com.ar/opinion/un-realismo-enrarecidoy-de-pesadilla-nid2257724.

CAMPRA, Rosalba (2008): Territorios de la ficción. Lo fantástico. Sevilla, Renacimiento.

CRIALES, José Pablo (2019): “El triunfo de las escritoras argentinas: 10 libros para empezar a leerlas". Verne. El Pais, el 5 de noviembre de 2019, disponible en. https://verne.elpais.com/verne/2019/11/05/mexico/1572908605_226000.html.

DRUCAROFF, Elsa (2016): “¿Qué cambió y qué continuó en la narrativa argentina desde Los prisioneros de la torre?". El matadero 10: 23-40.

GALLEGO CUIÑAS, Ana (2020): "Feminismo y literatura (argentina) mundial: Selva Almada, Mariana Enríquez y Samanta Schweblin". En Gustavo Guerrero-Jorge Joaquín Locane-Benjamin Loy-Gesine Müller: Literatura latinoamericana mundial: dispositivos y disidencias, vol. 5. Berlin, De Gruyter: 71-96. DOI: https://doi.org/10.1515/9783110673678-006

GASCÓN, Daniel: "Entrevista con Yanina Rosenberg: «Me parece mucho más interesante pensar en lo que no vemos que en lo que vemos»". Letras Libres, el 29 de marzo de 2019, disponible en: https://www.letraslibres.com/espana-mexico/literatura/entrevistayanina-rosenberg-me-parece-mucho-mas-interesante-pensar-en-lo-que-no-vemos-queen-lo-que-vemos. 
GOLOBOFF, Mario (2004): “Una literatura de puentes y pasajes: Julio Cortázar". En Noe Jitrik (dir.): Historia crítica de la literatura argentina, vol. 9, El oficio se afirma, dir. Sylvia Saítta. Buenos Aires, Emecé: 277-304.

HARAWAY, Donna (1995): Ciencia, cyborgs y mujeres. La reinvención de la naturaleza. Trad. Manuel Talens. Madrid, Cátedra/Universitat de Valencia-Instituto de la Mujer.

HOTTOIS, Gilbert: "Rostros del trans/posthumanismo a la luz de la pregunta por el humanismo", Revista Colombiana de Bioética X/2 (2015): 175-192. DOI: https://doi.org/10.18270/rcb.v10i2.1764

SARLO, Beatriz (2007): Escritos sobre literatura argentina. Buenos Aires, Siglo XXI.

TODOROV, Tzvetan (1995): Introducción a la literatura fantástica. Trad. Silvia Delpy. México, Ediciones Coyoacán.

VANGUARDIA, La: "La autora argentina Yanina Rosenberg lleva a sus cuentos el terror cotidiano", La Vanguardia, el 10 de febrero de 2019, disponible en: https://www.lavanguardia.com/vida/20190210/46333787680/la-autora-argentinayanina-rosenberg-lleva-a-sus-cuentos-el-terror-cotidiano.html.

(C) Graciela Sarti

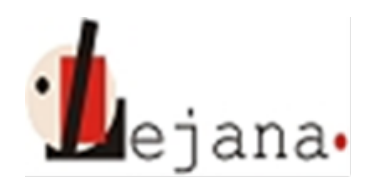

http://ojs.elte.hu/index.php/lejana

Universidad Eötvös Loránd, Departamento de Español, 1088 Budapest, Múzeum krt. 4/C 